\title{
The Etiology of Osteoarthritis of the Hip
}

\section{An Integrated Mechanical Concept}

\author{
Reinhold Ganz MD, Michael Leunig MD, \\ Katharina Leunig-Ganz MD, William H. Harris MD, DSc
}

(C) The Association of Bone and Joint Surgeons 2008

\begin{abstract}
The etiology of osteoarthritis of the hip has long been considered secondary (eg, to congenital or developmental deformities) or primary (presuming some underlying abnormality of articular cartilage). Recent information supports a hypothesis that so-called primary osteoarthritis is also secondary to subtle developmental abnormalities and the mechanism in these cases is femoroacetabular impingement rather than excessive contact stress. The most frequent location for femoroacetabular impingement is the anterosuperior rim area and the most critical motion is internal rotation of the hip in $90^{\circ}$ flexion. Two types of femoroacetabular impingement have been identified. Cam-type femoroacetabular impingement, more
\end{abstract}

Each author certifies that he or she has no commercial associations (eg, consultancies, stock ownership, equity interest, patent/licensing arrangements, etc.) that might pose a conflict of interest in connection with the submitted article.

R. Ganz, M. Leunig

University of Berne, Berne, Switzerland

R. Ganz

Department of Orthopaedics, Balgrist University Hospital,

Zurich, Switzerland

M. Leunig ( $\square)$

Hip Service, Department of Orthopaedics, Schulthess Clinic,

Lengghalde 2, CH-8008 Zurich, Switzerland

e-mail: michael.leunig@kws.ch

K. Leunig-Ganz

Maternity Department, Triemli City Hospital, Zurich,

Switzerland

W. H. Harris

Harvard Medical School, Massachusetts General Hospital Harris Orthopedic Biomechanics and Biomaterials Lab, Boston, MA, USA prevalent in young male patients, is caused by an offset pathomorphology between head and neck and produces an outside-in delamination of the acetabulum. Pincer-type femoroacetabular impingement, more prevalent in middleaged women, is produced by a more linear impact between a local (retroversion of the acetabulum) or general overcoverage (coxa profunda/protrusio) of the acetabulum. The damage pattern is more restricted to the rim and the process of joint degeneration is slower. Most hips, however, show a mixed femoroacetabular impingement pattern with cam predominance. Surgical attempts to restore normal anatomy to avoid femoroacetabular impingement should be performed in the early stage before major cartilage damage is present.

Level of Evidence: Level V, therapeutic study. See the Guidelines for Authors for a complete description of levels of evidence.

\section{Introduction}

Four decades ago, Murray [46] suggested a relationship between a rather subtle deformity of the proximal femur, which he called the "tilt deformity," to the subsequent development of osteoarthritis (OA) of the hip [46]. Because only anteroposterior (AP) radiographs were available, the deformity was not fully characterized, but the AP film suggested a mild degree of the deformity commonly occurring after a minimal slipped capital femoral epiphysis (SCFE). It appeared to foretell the later development of OA in the hip (Figs. 1, 2).

Stimulated by Murray's observations, Solomon and colleagues in South Africa [54-58] and Harris and colleagues in the United States [20-22, 61, 62] extended Murray's original suggestion. From these three sets of 
Fig. 1A-D AP radiographs of (A) a normal hip and three forms of abnormalities associated with mild slipped capital femoral epiphyses called (B) "flattening," (C) the "bump," and (D) the "hook." Reproduced with permission from Harris WH. Etiology of osteoarthritis of the hip. Clin Orthop Relat Res. 1986;213:22.

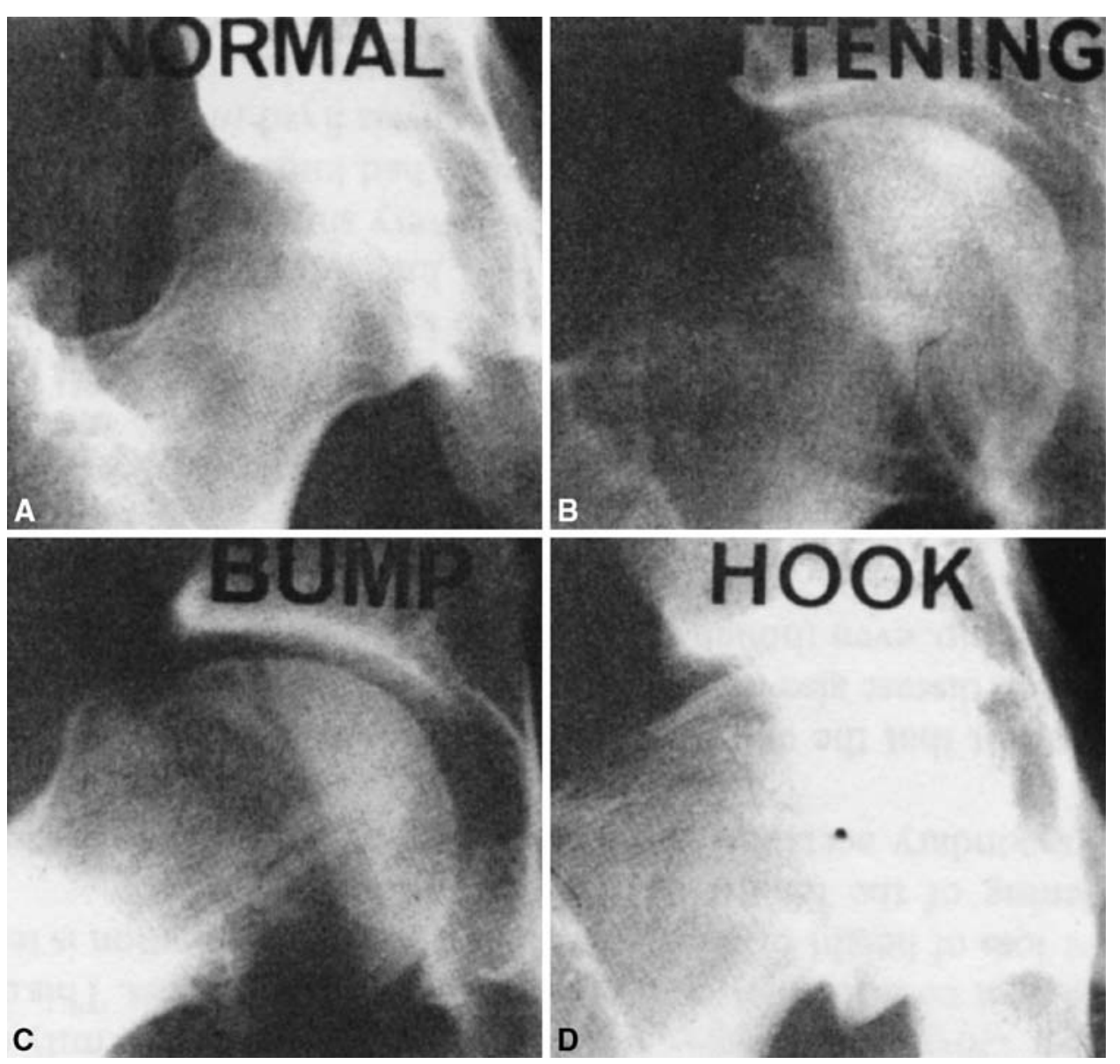

observations grew a controversial hypothesis on the etiology of hip OA [20-22, 54-58, 61, 62]: the theory proposes many cases of osteoarthritis of the hip that previously were considered "primary" or "idiopathic" are, indeed, caused by minor developmental deformities that were previously unrecognized or ignored and these deformities cause arthritis to develop from what is today called femoroacetabular impingement (FAI).

This overview integrates for the first time this previously proposed hypothesis on the etiology of hip OA into the concept of FAI recently proposed by Ganz et al. [17].

\section{History of the Theory}

The new theory first required an extensive set of exclusion criteria: inflammatory diseases of the hip (such as rheumatoid arthritis, ankylosing spondylitis, Reiter's syndrome, or lupus) as well as calcium pyrophosphate disease, diffuse idiopathic skeletal hyperostosis, gout, and hemochromatosis. Also excluded were osteonecrosis and fractures around the joint, including fracture of the acetabulum, femoral head, or femoral neck. Similarly, cases of damage to the cartilage from infection or resulting from penetration of a fixation device into the joint space were excluded. This set of exclusions was necessary to narrow the definition of hip OA to those causes that arise within the joint itself without extraneous inflammatory, traumatic, and metabolic causes, such as OA that can develop after an earlier septic damage or after rheumatoid arthritis has damaged the joint at an earlier time and has burned out as an active rheumatoid process.

Second, within this redefined group, several additional key observations were made. Clearly, many cases of hip OA result from severe developmental or acquired deformities of the hip that occurred in infancy or childhood. Children with developmental dysplasia resulting in a hypoplastic acetabular articulation coupled to a deformed femoral head often develop progressive and severe arthritis of the hip in late adolescence or young adult life. Similarly, some patients with severe SCFE or Legg-Calvé-Perthes disease may develop late OA. It is generally agreed hip OA in these examples is causally related to the gross deformity. In contrast, the focus of the new concept addressed those remaining cases of hip OA in which the deformity was considered mild, slight or even, in the eyes of casual observers, nonexistent. In the past, such cases have been commonly considered "primary" (ie, without known etiology). 


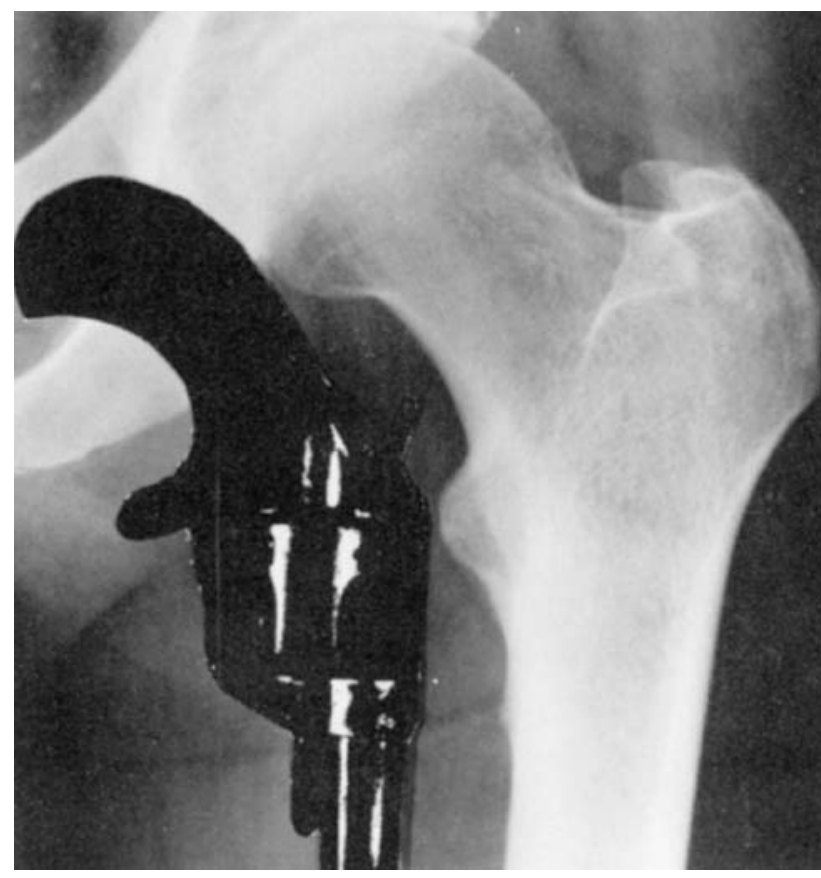

Fig. 2 Comparison of the mild deformity of the proximal femur secondary to a mild, unrecognized slipped capital femoral epiphysis and the contour of the grip of a pistol. Because of the similarity, these types of proximal femoral deformities are called "pistol grip deformities." Reproduced with permission and copyright (C) 1975 by Elsevier from Stulberg SD. Unrecognized childhood hip disease: a major cause of idiopathic osteoarthritis of the hip. In: Cordell LD, Harris WH, Ramsey PL, MacEwen GD, eds. The Hip: Proceedings of the Third Open Scientific Meeting of the Hip Society. St Louis, MO: CV Mosby; 1975:212-228.

It was in this group of patients with mild deformities that the hypothesis developed. Murray's [46] work suggested hip OA could develop secondary to rather subtle, sometimes previously unrecognized deformities that occurred before full skeletal maturation. One example was the development of hip OA secondary to a mild, unrecognized, and untreated SCFE. Harris and Solomon and their coworkers presented additional longitudinal data on documented cases of mild developmental hip disease unrecognized as abnormal by many radiologists and orthopaedic surgeons, which led years later to hip OA [20-22, 54-58, 61, 62]. The leading conditions contributing to these subtle deformities were developmental hip dysplasia, SCFE, Legg-Calvé-Perthes disease, multiple epiphyseal dysplasia, and spondyloepiphyseal dysplasia.

This concept was subsequently supported in retrospective analyses of patients presenting in adult life with hip OA, without any of the excluded conditions, for whom prior radiographs were available for analysis after adulthood had been reached, but before any radiographic signs of arthritis were visible. From these studies, a striking observation was made: $79 \%$ of these cases had antecedent subtle but definite signs of an underlying developmental abnormality [21, 61, 62].

Among women, unrecognized and untreated developmental dysplasia predominated [61]. Among men, the dominant abnormality was femoral, not acetabular, and had the characteristic of the "tilt" deformity on AP radiographs [62]. When assessed using three radiographic views (AP, frog lateral, and crosstable lateral), this femoral deformity was more fully described and named the "pistol grip" deformity [21, 62]. Detailed longitudinal followup studies of long duration confirmed this characteristic configuration of the femoral head and neck could be produced by several etiologies, namely SCFE, Legg-Calvé-Perthes disease, multiple epiphyseal dysplasia, and spondyloepiphyseal dysplasia. This same femoral deformity also existed in many patients, both male and female, who had developmental acetabular dysplasia. Thus, this common femoral deformity can exist both with and without an acetabular dysplasia. Moreover, as is well known, longitudinal studies show some cases of Legg-Calvé-Perthes disease that began as a purely femoral abnormality producing a pistol grip deformity can secondarily lead to acetabular deformity [21, 61, 62].

Thus, this concept is reinforced by evidence from both longitudinal studies following known cases of developmental dysplasia of the hip, SCFE, and Legg-Calvé-Perthes disease into adulthood and retrospective studies of adult cases of OA, which showed a high correlation between these hip deformities resulting from infantile, childhood, and adolescent conditions and the subsequent adult hip OA.

A retrospective study of Caucasian cases in the United States suggested $79 \%$ of the cases of adult OA were associated with these deformities, and when the remaining $21 \%$ of cases were further examined over a longer time span, an additional $10 \%$ had or subsequently developed signs of rheumatoid arthritis, hemochromatosis, or calcium pyrophosphate disease [21]. Thus, after eliminating the excluded conditions listed above that lead to degenerative changes in the hip, approximately $90 \%$ of the cases of adult hip OA were associated with some developmental abnormality.

Solomon et al. [54-58] made similar observations in Caucasians living in South Africa. Moreover, they made other relevant observations. They found a markedly lower incidence of hip OA in Africans in South Africa compared to Caucasians. This difference also correlated with a markedly lower incidence of those related developmental conditions listed above, conditions that were common among Caucasian children and adolescents in South Africa but uncommon among Africans. These parallel differences in Africans further suggested a causal role of developmental deformities of the hip in leading to adult hip OA [55]. This relationship between developmental deformities 
Fig. 3A-C (A) FAI is shown in a 34-year-old man with an apparently normal AP radiograph. (B) The nonspherical femoral head leading to reduced offset at the neck and predisposition to cam FAI is visible on the lateral radiograph. (C) The MRI scan confirmed the labral tear and chondral injury resulting from FAI. Reproduced with permission from Ganz R, Parvizi J, Beck M, Leunig M, Nötzli H, Siebenrock KA. Femoroacetabular impingement. Clin Orthop Relat Res. 2003;417:115.
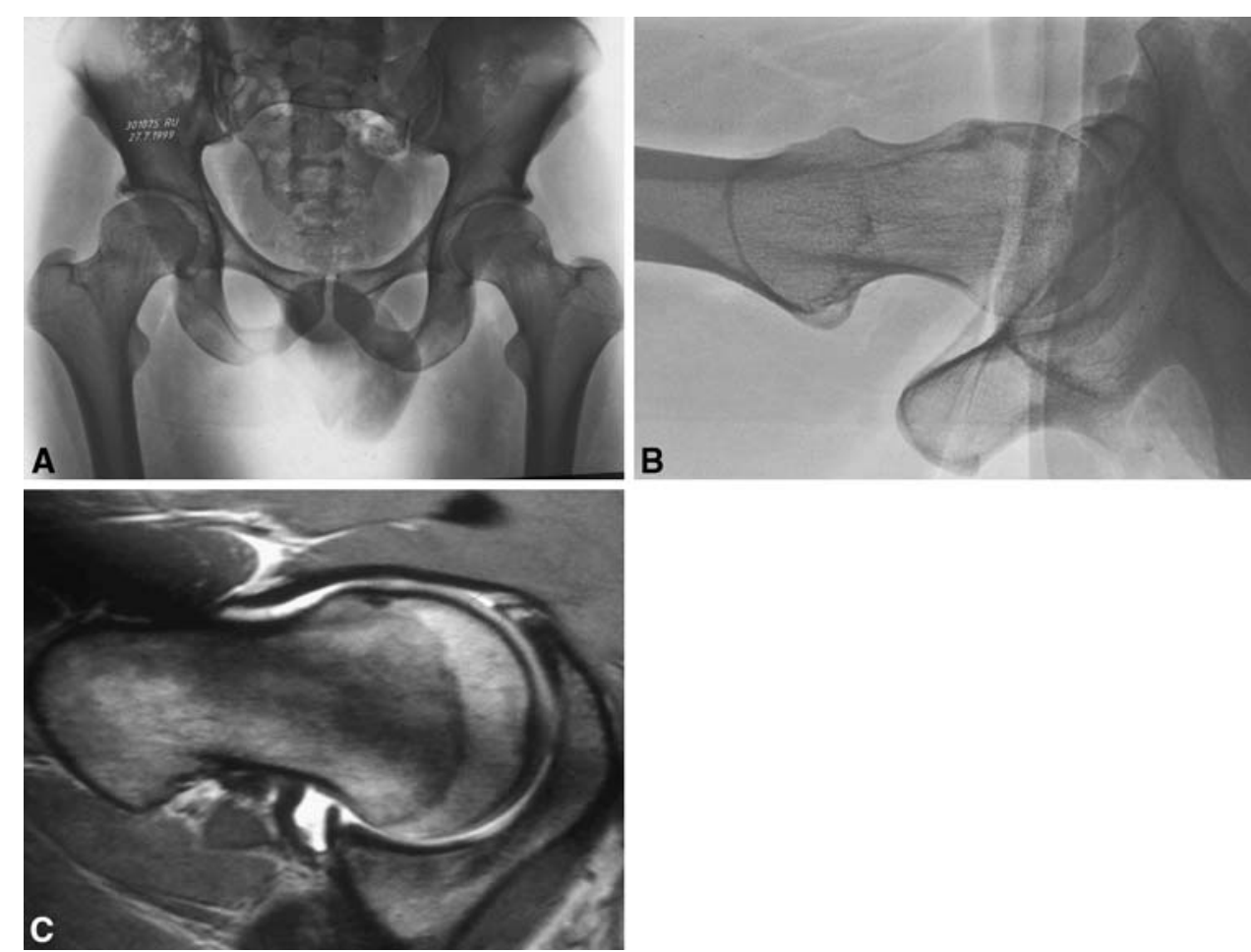

and subsequent $\mathrm{OA}$ was further reinforced by the identification by Solomon and coworkers of two "geographically isolated African communities in whom hip OA was unexpectedly common; in both, there is also a high incidence of hip dysplasia" [56].

A relationship between developmental deformities and hip OA is not new. For decades, many cases of hip OA have been called "secondary," for example, secondary to severe dysplasia. The distinction here lies in the novel concept that more subtle deformities, often unrecognized in the past as meaningful deformities, can produce hip OA (Fig. 3). This hypothesis proposes most, if not all, hip OA is secondary, often secondary to subtle but definite and commonly overlooked, ignored, or not recognized dysplasia or pistol grip deformities.

\section{Problems with the Theory}

While the data supporting this hypothesis appeared strong, several critical pieces were still missing. First was clinical confirmation. Large-scale radiographic studies of asymptomatic young adults to document the percentage of individuals with these developmental abnormalities could potentially provide confirmatory evidence. Prospective longitudinal long-term followup studies could demonstrate both the positive and negative predictive power of the hypothesis. Studies of this nature would contribute to such important questions as "do those patients with these abnormalities always get OA?" and "are these deformities the only ones to produce OA?"

The second piece of data missing was the mechanism by which some of these subtle abnormalities, for example, subtle femoral head, head-neck, or neck deformities, led to OA. In contrast to this question in relation to minor deformities, in cases of severe deformities, the joint contact area was typically reduced by distortion of the acetabulum or femoral head or both and thus the contact pressure history in the articular cartilage was increased. However, we do not believe a major reduction in contact area would be a satisfactory explanation in those cases of subtle deformities, for example, in cases having a normal acetabular contour and only a mildly abnormal head-neck contour.

The third missing piece, and perhaps most important to the patient with the subtle abnormality, was a way to treat the deformity and halt or delay the process. If these abnormalities were causally related to the generation of the OA, what could be done, surgically or otherwise, that could retard or eliminate the progression of the disease under circumstances of sufficiently low risk that such early intervention would be warranted?

Thus, this hypothesis lay in an uncertain state for 40 years, unconfirmed and yet tantalizing in its possible suggestion that if the mechanism of the osteoarthritic process from these deformities could be established, a solution to retard progressive damage might ensue. 


\section{Recent Evidence in Support of the Theory}

Two recent developments strengthen the hypothesis and play a predictive role in confirming the hypothesis. The two key developments are (1) the recognition of the mechanism for the development of the hip OA caused by mild deformities and (2) the possibility that correction of that mechanism could retard the development of the OA.

First pioneered and stimulated by Ganz and coworkers [4-6, 12, 14, 16-18, 23, 24, 30-36, 39-41, 47, 52, 53, 60, 66], and now confirmed by a variety of observations from many centers worldwide $[1-3,7-11,19,25,27,28,42,43$, $45,48-51,59,63-65,68,69]$, a mechanism has been defined that explains how these subtle developmental abnormalities adversely affect the joint and lead to OA in many cases. The dominant mechanism is FAI-induced by motion of the well-constrained hip. In those cases of severe deformity of the hip secondary to developmental abnormalities, the mechanism of OA is excessive contact stress history on the cartilage secondary to reduced contact area. This is not so for the more subtle deformities that produce
FAI since the contact areas are not reduced. The recognition of this important mechanism, however, could not be made until after the technique of surgical dislocation of the hip could be executed without the risk of avascular necrosis and had been developed in a way that produced little or no morbidity from the procedure $[15,16,18]$. Surgical dislocation of the hip allowed not only for in situ observation of the FAI process but also for the attribution of the various damage patterns within the joint to different FAI morphologies [4]. Although FAI can take place everywhere around the femoroacetabular joint, the most common site is anterolateral and is produced by internal rotation of the femur in flexion.

Two distinct types of FAI have been identified (Fig. 4). The first is characterized by the linear impact of the acetabular rim against the head-neck junction in a local (eg, acetabular retroversion) or global (eg, coxa profunda or protrusio) overcoverage of the acetabulum; it is therefore named pincer FAI. The second type occurs with the jamming of a nonspherical extension of the femoral head into the acetabular cavity; it is therefore named cam FAI [17].
Fig. 4A-D Diagrams illustrate the proposed mechanisms of joint damage in FAI. (A) In pincer FAI, linear impact due to the acetabular overcoverage occurs anteriorly. The persistent anterior abutment with chronic leverage of the head in the acetabulum sometimes results in chondral injury in the "contrecoup" region of the posterior-inferior acetabulum. (B) In cam FAI, the prominent femoral head/neck junction (C) is jammed into the acetabulum causing damage to the peripheral cartilage at flexion and internal rotation (D). Reproduced with permission from Lavigne $\mathrm{M}$, Parvizi J, Beck M, Siebenrock KA, Ganz R, Leunig M. Anterior femoroacetabular impingement. Part I. Techniques of joint preserving surgery. Clin Orthop Relat Res. 2004;418:71.
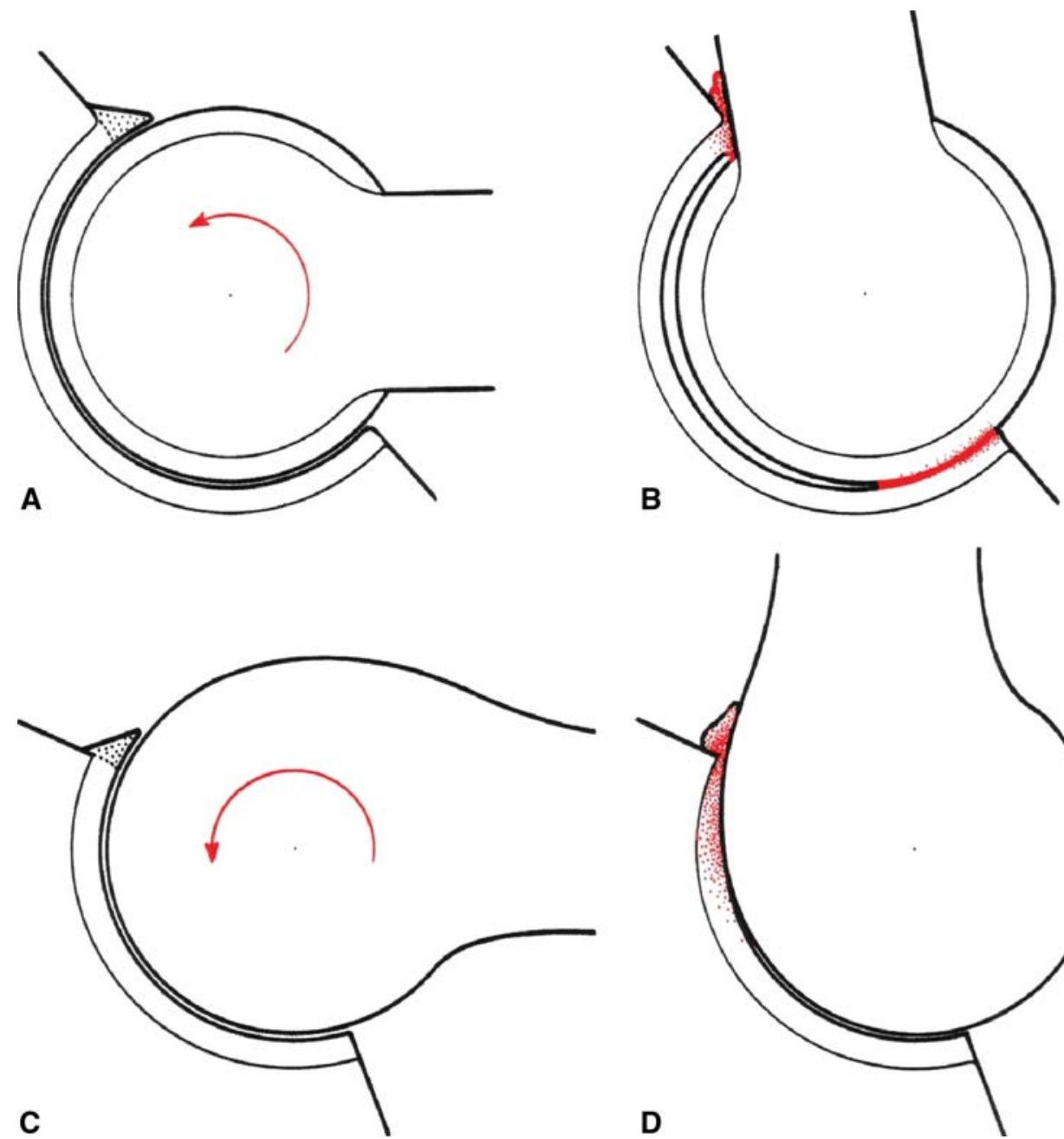

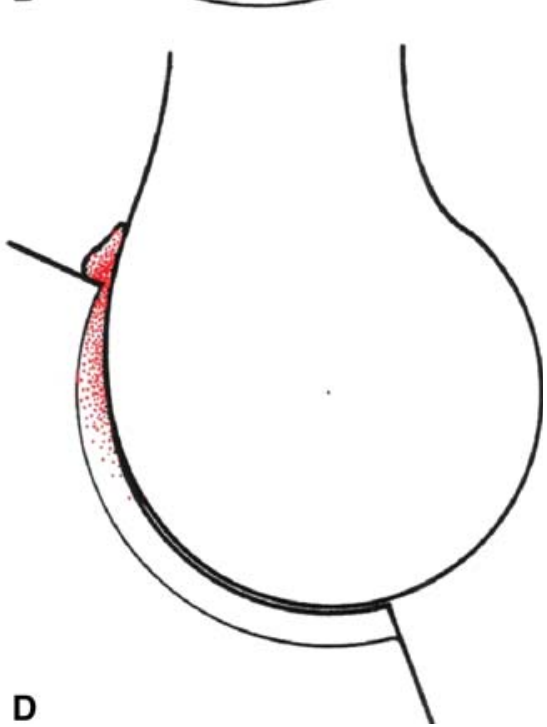


Both morphologic abnormalities are frequent and often combined [4]. With retroversion of the acetabulum, the ischial spine is in most cases visible in the pelvic cavity [26], suggesting a true rotational abnormality of the acetabulum. The nonsphericity of the femoral head is mostly located anterolaterally and therefore not necessarily visible on AP radiographs [44]. When it is seen on AP radiographs, it is known as pistol grip deformity [62]. Nonspherical extensions of the head are frequently the result of an abnormality of the capital femoral epiphysis [53] and are covered by hyaline cartilage [66]. However, the metaphysis in SCFE [37, 38], as well as other deformities of the proximal femur like Legg-Calvé-Perthes disease [13] or the retrotilt of an otherwise perfectly healed femoral neck fracture [12], can also produce a cam FAI.

The damage pattern of pincer and cam FAI differ substantially when one of these two types exists as an isolated deformity (Fig. 5). In pincer FAI, the first structure to fail is the labrum, showing intrasubstance fissuring and intrasubstance ganglion formation. With time, bone apposition occurs on the osseous rim next to the labrum, pushing the labrum forward. The labrum itself becomes thinner and thinner until it finally is no longer distinguishable. The bone apposition is visible on MRI [67] as well as on standard radiographs as a double line of the involved rim; as such, it increases impingement. The acetabular cartilage adjacent to the involved labrum undergoes degeneration, but in a rather thin strip. With time, the impact area on the femoral neck shows a saddlelike callus formation with central ulcerations of the periosteum. The femoral head cartilage remains uninvolved over a long period; only late in the process will there be cartilage abrasion in the posteroinferior joint, on the head, and/or on the acetabulum called "contrecoup lesion" [4].

In contrast, with isolated cam FAI, the labrum remains uninvolved over a rather long period. What appears on MRI as rupture of the labrum is in fact an avulsion of the acetabular cartilage from the labrum and then of the subchondral bone. Such a cartilage cleavage can become as deep as $2 \mathrm{~cm}$ and will be destroyed with time. When the involved area is large enough, the femoral head will migrate into the defect, which can be seen first in MRI and somewhat later in conventional radiography as joint space narrowing. It is only then that the cartilage of the spherical portion of the head (weightbearing area) becomes involved, while the cartilage of the nonspherical portion of the head (nonweightbearing area) shows surface damage early in the disease process $[17,66]$. Very often with cam FAI, cysts develop in the head or near the head-neck junction but always distal to the physis; we believe they reflect the effects of the jamming process [34].

The pincer-type FAI produces a rather slow process of degeneration and occurs more often in women between 30 and 40 years of age engaging in activities with high demands on motion like yoga and aerobics. The cam-type FAI is typically seen in athletic men on average a decade younger. Both FAI types produce damage first on the acetabular side, but cam FAI is clearly more destructive than pincer FAI, although the symptoms are often less pronounced. The more severe damage to the labrum, known to contain nociceptive fibers [29], is the most likely explanation for the increased pain reported by women suffering from pincer FAI compared to men with cam FAI.

The described damages to the hip produced by impingement are more than just precursors. They are the early stages of an extensive, generalized arthritic process of the joint. This concept of FAI applies to both the subtle and some of the larger deformities of the acetabular and the femoral side compromising the clearance of the hip for motion; it even includes a small group of patients with rather normal hip morphology but supraphysiologic demands on hip motion. Hips with cam FAI fail toward an anterosuperior OA while hips with pincer FAI fail toward a posteroinferior or central OA.

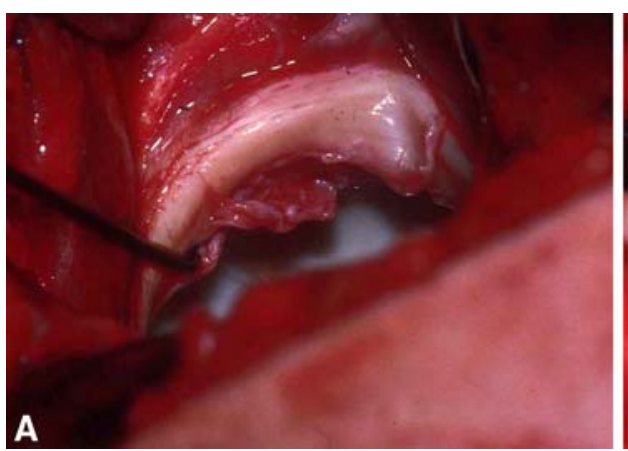

Fig. 5A-B Intraoperative photographs show acetabular cartilage damage during the treatment of young adult patients suffering from FAI. (A) In pincer FAI, the linear impact leads to substantial labral damage, while in early phases the adjacent cartilage remains intact.

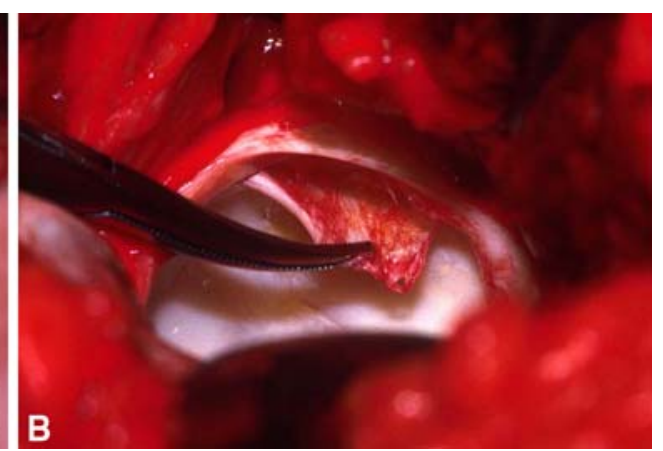

(B) In contrast, cam FAI frequently reveals deep-reaching flaplike cleavage lesions of cartilage from the subchondral bone early in the disease. 


\section{Discussion}

More than 40 years ago, Murray [46], Solomon et al. [5458], and Harris et al. [20-22, 61, 62] made the remarkable observation that primary OA of the hip could frequently be attributed to minor morphologic abnormalities such as pistol grip deformity. Until recently, the pathophysiology of this etiologic concept remained under debate.

To date, however, there is increasing evidence the FAI mechanism is the cornerstone of this mechanical etiologic concept of hip OA, which evolved some 40 years ago [21, $46,54]$, leaving few cases with so-called primary OA. With proposing this "novel" FAI concept, we also realized clinical and radiographic methods routinely used for advanced hip OA are limited, if not insufficient, for FAI assessment and documentation of treatment outcome.

Nonetheless, further steps are required to evaluate this hypothesis of OA of the hip. All are in process. In an unpublished sheep model, a $15^{\circ}$ varus osteotomy of the proximal femur produced an impingement of the hip and consequently showed lesions of the acetabular rim and of the adjacent cartilage typically seen in a mixed impingement. Increasing numbers of patients have been reported with detailed visual [4, 34] or arthroscopic documentation $[10,11,19,28,49-51,68]$ of the FAI partially followed by documented surgical correction of the morphologic abnormality leading to FAI. The short-term outcomes appear favorable [6, 10, 14, 19, 25, 28, 45, 48-52, 63], especially when comparing refixation of the labrum as part of the treatment steps versus débridement of the labrum [14]. The results of the joint reconstruction together with labral refixation favor the expectations of good long-term results. Substantial retardation of the development of OA would be both beneficial to the patient and supportive of the concept that such $\mathrm{OA}$ is caused in the described way. Nevertheless, before FAI treatment can be widely promoted, we require greater scrutiny to determine the right patient, the right time, and the right surgeon. It will not be the type of procedure (open or arthroscopic), but rather the possible intraarticular reconstruction that will determine treatment success or failure. The achievable intraarticular reconstruction will depend on the complexity of the FAI morphology and the degree of secondary degeneration.

Since 2005, a prospective population-based study has been underway (NFP53 405340-104778). Based on a cohort of more than 1100 young men, this study was initiated to address the prevalence of FAI in this population and to determine whether these morphologic alterations are associated with an increased rate of early OA (natural course study). Preliminary results suggest a decrease of internal rotation of the hip while at $90^{\circ}$ of flexion by $10^{\circ}$ increases the prevalence of acetabular rim pathology by a factor of two.
There is an increasing body of evidence that most hips that fail to OA without severe deformities of the joint do so with the mechanism of FAI based on subtle or moderate morphologic abnormalities of the joint components. An increasing number of such hips fail at a rather young age. Consequently, the strategy of treatment should be to reconstruct a hip morphology allowing motion not interrupted by FAI before major rim and cartilage damage is established. Because FAI treatment is most successful in the absence of secondary degenerative changes, this raises the question whether FAI treatment should be performed in "asymptomatic" patients. Most authors and surgeons view symptomatic as having pain. If the patient has a limited hip range of motion (flexion/internal rotation) and degenerative changes on MRI or radiography, treatment of FAI might be warranted even in the absence of pain. Presentation of a pain-free patient in the doctor's office is a rather rare situation and the decision-making process should involve the patient.

To have a standardized instrument for evaluation of such surgical indications but also for more accurate followup data, new scores for clinical evaluation, and imaging classification for the FAI hip ahead of the wellestablished OA are currently under development. A number of aspects of the concept of FAI are still not adequately confirmed; others are in the process of evaluation. Despite the increasing evidence favoring the concept, we believe treatment of FAI should currently be restricted to centers experienced in this pathology and staffed by surgeons adequately trained in techniques addressing FAI. Clinical and radiographic assessment and followup have to at least meet those required for total hip arthroplasty. If the above-mentioned developments and data collection take place, FAI treatment might become a mainstay in jointpreserving treatment of the hip similar to that of hip dysplasia.

\section{References}

1. Armfield DR, Towers JD, Robertson DD. Radiographic and MR imaging of the athletic hip. Clin Sports Med. 2006;25:211-239, viii.

2. Beall DP, Sweet CF, Martin HD, Lastine CL, Grayson DE, Ly JQ, Fish JR. Imaging findings of femoroacetabular impingement syndrome. Skeletal Radiol. 2005;34:691-701.

3. Beaule PE, Zaragoza E, Motamedi K, Copelan N, Dorey FJ. Three-dimensional computed tomography of the hip in the assessment of femoroacetabular impingement. J Orthop Res. 2005;23:1286-1292.

4. Beck M, Kalhor M, Leunig M, Ganz R. Hip morphology influences the pattern of damage to the acetabular cartilage: femoroacetabular impingement as a cause of early osteoarthritis of the hip. J Bone Joint Surg Br. 2005;87:1012-1018.

5. Beck M, Leunig M, Clarke E, Ganz R. Femoroacetabular impingement as a factor in the development of nonunion of the 
femoral neck: a report of three cases. J Orthop Trauma. 2004;18:425-430.

6. Beck M, Leunig M, Parvizi J, Boutier V, Wyss D, Ganz R. Anterior femoroacetabular impingement: part II. Midterm results of surgical treatment. Clin Orthop Relat Res. 2004;418:67-73.

7. Bharam S. Labral tears, extra-articular injuries, and hip arthroscopy in the athlete. Clin Sports Med. 2006;25:279-292, ix.

8. Blankenbaker DG, Tuite MJ. The painful hip: new concepts. Skeletal Radiol. 2006;35:352-370.

9. Bredella MA, Stoller DW. MR imaging of femoroacetabular impingement. Magn Reson Imaging Clin N Am. 2005;13:653664.

10. Clohisy JC, McClure JT. Treatment of anterior femoroacetabular impingement with combined hip arthroscopy and limited anterior decompression. Iowa Orthop J. 2005;25:164-171.

11. Crawford JR, Villar RN. Current concepts in the management of femoroacetabular impingement. J Bone Joint Surg Br. 2005;87: 1459-1462.

12. Eijer H, Myers SR, Ganz R. Anterior femoroacetabular impingement after femoral neck fractures. J Orthop Trauma. 2001;15:475-481.

13. Eijer H, Podeszwa D, Ganz R, Leunig M. Evaluation and treatment of young adults with femoro-acetabular impingement secondary to Perthes' disease. Hip Int. 2006;16:273-280.

14. Espinosa N, Rothenfluh DA, Beck M, Ganz R, Leunig M. Treatment of femoro-acetabular impingement: preliminary results of labral refixation. J Bone Joint Surg Am. 2006;88:925-935.

15. Ganz K, Krügel N. Die Arteria circumflexa femoris lateralis. Topographischer Verlauf, Anastomosen. Berne, Switzerland: Department of Orthopaedic Surgery, University of Berne; 1997.

16. Ganz R, Gill TJ, Gautier E, Ganz K, Krugel N, Berlemann U. Surgical dislocation of the adult hip: a technique with full access to the femoral head and acetabulum without the risk of avascular necrosis. J Bone Joint Surg Br. 2001;83:1119-1124.

17. Ganz R, Parvizi J, Beck M, Leunig M, Notzli H, Siebenrock KA. Femoroacetabular impingement: a cause for osteoarthritis of the hip. Clin Orthop Relat Res. 2003;417:112-120.

18. Gautier E, Ganz K, Krugel N, Gill T, Ganz R. Anatomy of the medial femoral circumflex artery and its surgical implications. J Bone Joint Surg Br. 2000;82:679-683.

19. Guanche CA, Bare AA. Arthroscopic treatment of femoroacetabular impingement. Arthroscopy. 2006;22:95-106.

20. Harris WH. Primary osteoarthritis of the hip: a vanishing diagnosis. J Rheumatol. 1983;Suppl 9:64.

21. Harris WH. Etiology of osteoarthritis of the hip. Clin Orthop Relat Res. 1986;213:20-33.

22. Harris WH, Bourne RB, Oh I. Intra-articular acetabular labrum: a possible etiological factor in certain cases of osteoarthritis of the hip. J Bone Joint Surg Am. 1979;61:510-514.

23. Ito K, Leunig M, Ganz R. Histopathologic features of the acetabular labrum in femoroacetabular impingement. Clin Orthop Relat Res. 2004;429:262-271.

24. Ito K, Minka MA 2nd, Leunig M, Werlen S, Ganz R. Femoroacetabular impingement and the cam-effect: a MRI-based quantitative anatomical study of the femoral head-neck offset. J Bone Joint Surg Br. 2001;83:171-176.

25. Jager M, Wild A, Westhoff B, Krauspe R. Femoroacetabular impingement caused by a femoral osseous head-neck bump deformity: clinical, radiological, and experimental results. J Orthop Sci. 2004;9:256-263.

26. Kalberer F, Sierra RJ, Madan SS, Ganz R, Leunig M. Projection of the ischial spine into the pelvic cavity: a new sign for acetabular retroversion on plain radiographs. Clin Orthop Relat Res. 2008; doi:10.1007/s11999-007-0058-6.

27. Kassarjian A, Yoon LS, Belzile E, Connolly SA, Millis MB, Palmer WE. Triad of MR arthrographic findings in patients with cam-type femoroacetabular impingement. Radiology. 2005;236: 588-592.

28. Kelly BT, Weiland DE, Schenker ML, Philippon MJ. Arthroscopic labral repair in the hip: surgical technique and review of the literature. Arthroscopy. 2005;21:1496-1504.

29. Kim YT, Azuma H. The nerve endings of the acetabular labrum. Clin Orthop Relat Res. 1995;320:176-181.

30. Lavigne M, Kalhor M, Beck M, Ganz R, Leunig M. Distribution of vascular foramina around the femoral head and neck junction: relevance for conservative intracapsular procedures of the hip. Orthop Clin North Am. 2005;36:171-176, viii.

31. Lavigne M, Parvizi J, Beck M, Siebenrock KA, Ganz R, Leunig M. Anterior femoroacetabular impingement: part I. Techniques of joint preserving surgery. Clin Orthop Relat Res. 2004;418:61-66.

32. Leunig M, Beck M, Dora C, Ganz R. Femoroacetabular impingement: etiology and surgical concept. Oper Tech Orthop. 2005; 15:247-255.

33. Leunig M, Beck M, Dora C, Ganz R. Femoroacetabuläres Impingement als Auslöser der Koxarthrose. Orthopade. 2006;35: 77-84.

34. Leunig M, Beck M, Kalhor M, Kim YJ, Werlen S, Ganz R. Fibrocystic changes at anterosuperior femoral neck: prevalence in hips with femoroacetabular impingement. Radiology. 2005;236: 237-246.

35. Leunig M, Beck M, Stauffer E, Hertel R, Ganz R. Free nerve endings in the ligamentum capitis femoris. Acta Orthop Scand. 2000;71:452-454.

36. Leunig M, Beck M, Woo A, Dora C, Kerboull M, Ganz R. Acetabular rim degeneration: a constant finding in the aged hip. Clin Orthop Relat Res. 2003;413:201-207.

37. Leunig M, Casillas MM, Hamlet M, Hersche O, Nötzli H, Slongo T, Ganz R. Slipped capital femoral epiphysis: early mechanical damage to the acetabular cartilage by a prominent femoral metaphysis. Acta Orthop Scand. 2000;71:370-375.

38. Leunig M, Fraitzl CR, Ganz R. Early damage to the acetabular cartilage in slipped capital femoral epiphysis: therapeutic consequences [in German]. Orthopade. 2002;31:894-899.

39. Leunig M, Ganz R. Femoroacetabuläres Impingement: Häufige Ursache von zur Arthrose führenden Hüftbeschwerden. Unfallchirurg. 2005;108:9-10, 12-17.

40. Leunig M, Parvizi J, Ganz R. Nonarthroplasty surgical treatment of hip osteoarthritis. Instr Course Lect. 2006;55:159-166.

41. Leunig M, Podeszwa D, Beck M, Werlen S, Ganz R. Magnetic resonance arthrography of labral disorders in hips with dysplasia and impingement. Clin Orthop Relat Res. 2004;418:74-80.

42. Mardones RM, Gonzalez C, Chen Q, Zobitz M, Kaufman KR, Trousdale RT. Surgical treatment of femoroacetabular impingement: evaluation of the effect of the size of the resection. J Bone Joint Surg Am. 2005;87:273-279.

43. Mardones RM, Gonzalez C, Chen Q, Zobitz M, Kaufman KR, Trousdale RT. Surgical treatment of femoroacetabular impingement: evaluation of the effect of the size of the resection. Surgical technique. J Bone Joint Surg Am. 2006;88(Suppl 1 Pt 1):84-91.

44. Meyer DC, Beck M, Ellis T, Ganz R, Leunig M. Comparison of six radiographic projections to assess femoral head/neck asphericity. Clin Orthop Relat Res. 2006;445:181-185.

45. Murphy S, Tannast M, Kim YJ, Buly R, Millis MB. Débridement of the adult hip for femoroacetabular impingement: indications and preliminary clinical results. Clin Orthop Relat Res. 2004;429:178-181.

46. Murray RO. The aetiology of primary osteoarthritis of the hip. $\mathrm{Br}$ J Radiol. 1965;38:810-824.

47. Nork SE, Schar M, Pfander G, Beck M, Djonov V, Ganz R, Leunig M. Anatomic considerations for the choice of surgical approach for hip resurfacing arthroplasty. Orthop Clin North Am. 2005;36:163-170, viii. 
48. Peters CL, Erickson JA. Treatment of femoro-acetabular impingement with surgical dislocation and débridement in young adults. J Bone Joint Surg Am. 2006;88:1735-1741.

49. Philippon MJ, Schenker ML. A new method for acetabular rim trimming and labral repair. Clin Sports Med. 2006;25:293-297, ix.

50. Philippon MJ, Schenker ML. Arthroscopy for the treatment of femoroacetabular impingement in the athlete. Clin Sports Med. 2006;25:299-308, ix.

51. Sampson TG. Arthroscopic treatment of femoroacetabular impingement: a proposed technique with clinical experience. Instr Course Lect. 2006;55:337-346.

52. Siebenrock KA, Schoeniger R, Ganz R. Anterior femoro-acetabular impingement due to acetabular retroversion: treatment with periacetabular osteotomy. J Bone Joint Surg Am. 2003;85: 278-286.

53. Siebenrock KA, Wahab KH, Werlen S, Kalhor M, Leunig M, Ganz R. Abnormal extension of the femoral head epiphysis as a cause of cam impingement. Clin Orthop Relat Res. 2004;418:54-60.

54. Solomon L. Patterns of osteoarthritis of the hip. J Bone Joint Surg Br. 1976;58:176-183.

55. Solomon L. Studies on the pathogenesis of osteoarthritis of the hip. Trans Coll Med South Africa. 1981:104-124.

56. Solomon L. Geographical and anatomical patterns of osteoarthritis. Br J Rheumatol. 1984;23:177-180.

57. Solomon L, Beighton P. Osteoarthrosis of the hip and its relationship to pre-existing in an African population. $J$ Bone Joint Surg Br. 1973;55:216-217.

58. Solomon L, Schnitzler CM, Browett JP. Osteoarthritis of the hip: the patient behind the disease. Ann Rheum Dis. 1982;41:118-125.

59. Sozen YV, Ozkan K, Goksan SB, Ciftci F, Mutlu S, Uzer G. Arthroscopic diagnosis and treatment of an acetabular labrum bucket handle tear: a case report. Arch Orthop Trauma Surg. 2005; 125:649-652.
60. Strehl A, Ganz R. Anterior femoroacetabular impingement after healed femoral neck fractures [in German]. Unfallchirurg. 2005; 108:263-273.

61. Stulberg SD. Acetabular dysplasia, development of osteoarthritis of the hip. In: Harris WH, ed. The Hip: Proceedings of the Second Open Scientific Session of the Hip Society. St Louis, MO: CV Mosby; 1974:82-93.

62. Stulberg SD. Unrecognized childhood hip disease: a major cause of idiopathic osteoarthritis of the hip. In: Cordell LD, Harris WH, Ramsey PL, MacEwen GD, eds. The Hip: Proceedings of the Third Open Scientific Meeting of the Hip Society. St Louis, MO: CV Mosby; 1975:212-228.

63. Tanzer M, Noiseux N. Osseous abnormalities and early osteoarthritis: the role of hip impingement. Clin Orthop Relat Res. 2004;429:170-177.

64. Theumann N, Wettstein M. Clinical and radiological aspects of femoro-acetabular impingement [in French]. Rev Med Suisse. 2006;2:1741-1746.

65. Tschauner C, Fock C, Hofmann S. Femoro-acetabular impingement: an underestimated pathogenetic factor in coxarthrosis [in German]. Z Orthop Ihre Grenzgeb. 2001;139:M88-M91.

66. Wagner S, Hofstetter W, Chiquet M, Mainil-Varlet P, Stauffer E, Ganz R, Siebenrock KA. Early osteoarthritic changes of human femoral head cartilage subsequent to femoro-acetabular impingement. Osteoarthritis Cartilage. 2003;11:508-518.

67. Werlen S, Leunig M, Ganz R. Magnetic resonance arthrography of the hip in femoroacetabular impingement: technique and findings. Oper Tech Orthop. 2005;15:191-203.

68. Wettstein M, Dienst M. Hip arthroscopy for femoroacetabular impingement [in German]. Orthopade. 2006;35:85-93.

69. Wisniewski SJ, Grogg B. Femoroacetabular impingement: an overlooked cause of hip pain. Am J Phys Med Rehabil. 2006;85: 546-549. 